\title{
Characterisation of sand-steel interface shearing behaviour for the interpretation of driven pile behaviour in sands
}

\author{
Tingfa Liu ${ }^{1, *}$, Haoruo Chen $^{2}$, Róisín M. Buckley ${ }^{3}$, V. Santiago Quinteros ${ }^{1,4}$, and Richard J. Jardine ${ }^{1}$ \\ ${ }^{1}$ Imperial College London, UK \\ ${ }^{2}$ CCCC Highway Consultants, Co. Ltd, Beijing, China; formerly Imperial College London, UK \\ ${ }^{3}$ University of Oxford, UK; formerly Imperial College London, UK \\ ${ }^{4}$ Norwegian Geotechnical Institute, Oslo, Norway
}

\begin{abstract}
The installation and loading of steel piles driven in sands modifies both the piles' surface topography and the characteristics of the granular materials present adjacent to the pile shaft. Largedisplacement ring shear interface tests incorporating pre-conditioning stages are capable of reproducing such physical processes in the laboratory and can generate case-specific interface design parameters. This paper summarises laboratory research that characterised the interface shearing behaviour of three natural sandy soils retrieved from field test sites (Dunkirk, France; Blessington, Ireland; Larvik, SE Norway) where extensive piling studies on micro and industrial scale driven piles have been carried out. The programme examined the influences of soil characteristics (physical properties and chemical compositions), interface type (mild steel or stainless steel) and surface roughness, and highlighted the significant effects of normal effective stress level and ageing time duration. Remarkable trends of increasing interface friction angles with elevated normal effective stress levels and prolonged ageing were observed. The results from supplementary smalldisplacement direct shear interface tests and triaxial tests are also reported. The experiments are interpreted with reference to earlier studies to develop an overview of interface shearing characteristics between steels and sandy soils and provide important insights into the mechanisms of axial capacity increases applying to steel piles driven in sands.
\end{abstract}

\section{Introduction}

Extensive studies into offshore piled foundations have advanced current understanding of pile behaviour under various loading conditions and led to the development of improved design guidelines, for example the CPT-based ICP design approaches for driven piles in sands and clays [1], and the PISA design methods tailored for offshore monopile foundations [2]. Significant ageing increases in driven pile shaft capacities over time in sands have been investigated in a series of field and model studies, see for examples [3-7]. The latter authors proposed that the following ageing mechanisms may govern the shaft capacity increases observed over weeks and months in the field:

$\# 1$. Stress redistribution leading to elevated stationary radial effective stresses $\left(\sigma_{\mathrm{rc}}{ }^{\prime}\right)$ acting on the shafts,

\#2. Enhanced dilation at the sand-shaft interface and increases in sand stiffnesses over time;

\#3. Physicochemical processes around pile shafts that involve the sands, groundwater and pile shaft materials.

[7] summarised normalised static tension capacityageing time trends for industrial scale (with 340 to 508 $\mathrm{mm}$ outer diameter, up to $21 \mathrm{~m}$ length) piles driven at Blessington (Ireland), Dunkirk (France) and Larvik (Norway) sand sites, as shown in Fig. 1. [8] reported a comparable trend established from an extended ZJU-ICL database of driven pile tests in sand.

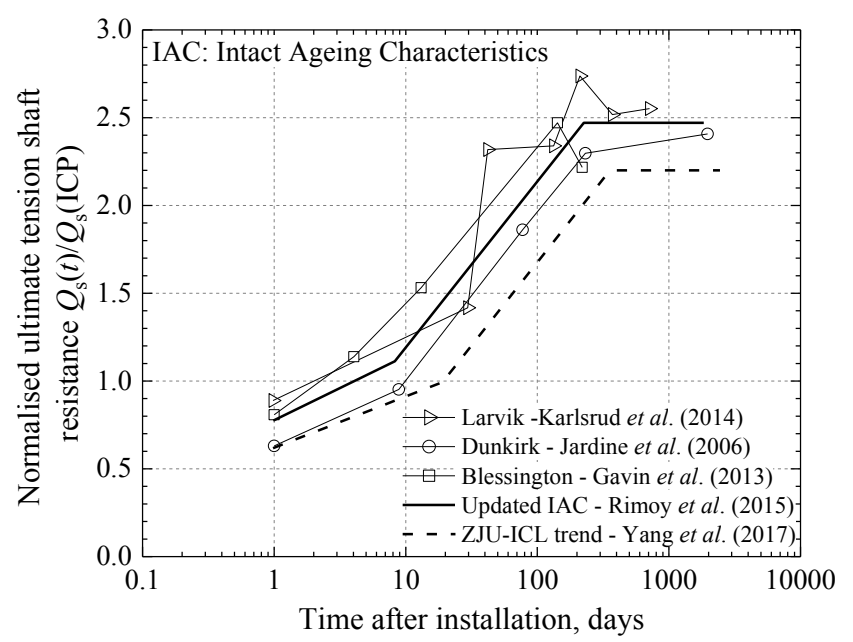

Fig. 1. Normalised static tension capacity- ageing time trends established for industrial-scale steel piles [7-8]

Further tension pile tests were carried out at these sites on 51 micro-piles (with $48-60 \mathrm{~mm}$ outer diameter, 1.75 $2.4 \mathrm{~m}$ contact length) that were made of different types of steel (stainless, galvanised and mild steel) with a range of surface roughnesses (centre-line average roughness, $R_{\mathrm{CLA}}$ ranging 1-10 $\mu \mathrm{m})$. The latter were tested after ageing

\footnotetext{
*orresponding author: t.liu14@imperial.ac.uk
} 
periods of 0.1 to 696 days, as described by [9]. The field test outcome generated new insights into ageing and led to re-evaluation of some input parameters for micro piles when adopting the ICP-05 design method. The micro-pile tests demonstrated that corrosion reactions are central to ageing shaft capacity gains.

Parallel laboratory studies were launched at Imperial College London (ICL) on the three sites' sandy soils. [10] and [11] reported on the sand-steel shearing resistance and dilation characteristics that govern pile shaft capacity. Their laboratory studies aimed to: (i) generate sitespecific sand-steel interface shearing friction angles $\left(\delta^{\prime}\right)$ that were essential for interpreting and predicting shaft capacities of the historic and recent field pile tests; (ii) investigate the effects on interface friction angle and dilation of a range of influential factors; (iii) examine the above ageing mechanisms under well-controlled laboratory conditions; (iv) quantify changes to the soils' and steel interfaces' physical and chemical properties due to interface shearing and ageing, with the aid of post-test sub-sampling procedures, optical and laser imaging techniques and chemical index testing.

This paper sets out first the soil properties, testing methodology and programmes, followed by illustrative results and discussion that focuses on examining the above ageing mechanisms from a laboratory testing perspective.

\section{Soil properties}

Blessington, Dunkirk and Larvik sands have distinctive mineralogical and chemical properties that reflect their varied origins, as summarised in Table 1. [9] reported that the Larvik sand contained minimal carbonate composition, but has a significantly high sulphate content with $\mathrm{pH}$ in the acidic range $(<7)$, reflecting its igneous origin and possible industrial contamination. The Blessington and Dunkirk sands show alkaline $\mathrm{pH}$ values and contain low-to-medium calcium carbonate contents with broadly similar chemical compositions, featuring the limestone origin of the glacial Blessington sand and the nearshore origin of the shelly Dunkirk sand.

Table 1 Mineralogical and chemical compositions of the sands

\begin{tabular}{c|l}
\hline Sand & \multicolumn{1}{|c}{ Mineralogical/chemical composition } \\
\hline $\begin{array}{c}\text { Blessington } \\
\text { sand }\end{array}$ & $\begin{array}{l}\text { Highly angular quartz, calcite feldspar, } \\
\text { muscovite mica; around 20\% carbonate } \\
\text { content }\end{array}$ \\
\hline $\begin{array}{c}\text { Dunkirk } \\
\text { sand }\end{array}$ & $\begin{array}{l}84 \% \mathrm{SiO}_{2} \text { quartz, 8\% feldspar, 8\% calcium } \\
\text { carbonate shell fragments; lower carbonate } \\
\text { content was expected under test condition due } \\
\text { to manual removal of large shell fragments }\end{array}$ \\
\hline Larvik sand & $\begin{array}{l}\text { 25\% quartz, 37\% feldspars and 38\% } \\
\text { plagioclase, no clay mineral; minimal } \\
\text { carbonate content }\end{array}$ \\
\hline
\end{tabular}

The grain size distributions of the three materials are plotted in Fig. 2, noting the Dunkirk sand's relatively uniform grain sizes and the Blessington and Larvik sands' inclusion of significant fines contents (6-7\%).

Naturally, the sands' physical and chemical properties contribute to their laboratory interface shearing behaviour, as later demonstrated, and the age-dependent tension capacity of the field piles, as presented by [9].

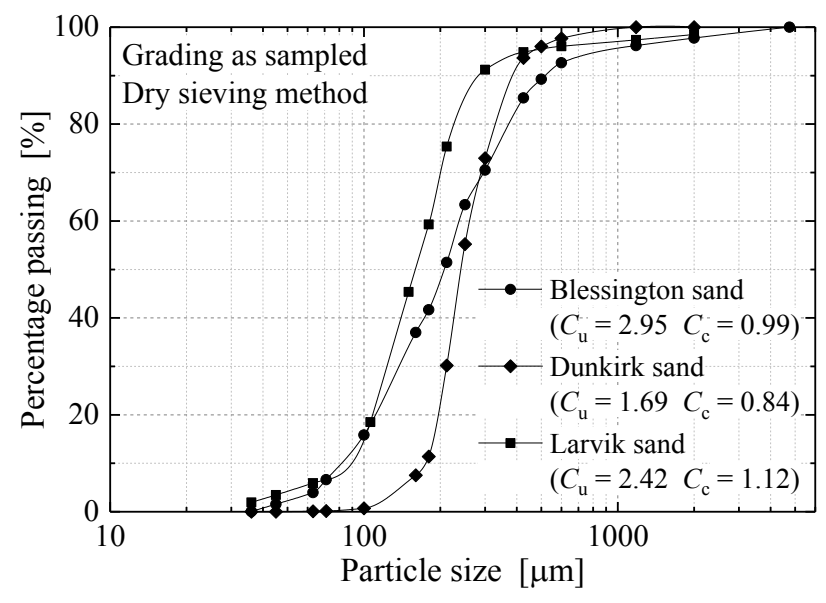

Fig. 2. Particle size distribution of the tested sands

\section{Experimental programme}

The research programme completed by [10] and [11] consisted of 29 large-displacement Bishop ring shear sand-steel interface tests on the three soils and 9 smalldisplacement direct shear interface tests on Dunkirk sand. Table 2 provides an overview of the testing programme, summarising key information regarding interface steel type and surface roughness, normal effective stress level $\left(\sigma_{\mathrm{n}}{ }^{\prime}\right)$ and consolidation (ageing) time. Supplementary drained triaxial tests and high-pressure oedometer tests were performed that revealed important features of sandsand shearing resistance features, compression and crushing characteristics. The employed testing apparatuses and methodology are described below. Illustrative triaxial, direct shear and ring shear test results from primary Dunkirk sand tests are discussed subsequently.

\subsection{Large-displacement Bishop ring shear interface tests with pre-conditioning}

The Bishop type ring shear apparatus [12], as illustrated in Fig. 3, offers a robust tool for characterising soil-soil and soil-structure residual shear strengths. Site-specific ring shear interface tests are recommended by [1] as an effective approach for deriving representative interface friction angles for the detailed design of driven piles in clays [13], sands [14-17] and other geo-materials including chalk [18]. [19] summarise the important aspects of upgrade and modifications implemented to the Bishop ring shear apparatuses at Imperial College London (ICL) and Norwegian Geotechnical Institute (NGI), and present a unified database for sand/silt-steel interface shear tests that followed the 'ICP' procedures [1]. 
A fast, large-displacement (around $5 \mathrm{~m}$ ) preconditioning shearing stage is applied after initial consolidation and creep stages to replicate pile driving, which is accompanied by significant changes in the steel interfaces' surface characteristics and also the properties of sands adjacent to pile shaft, as revealed by [14] and [20].

The fast shearing stages are applied under constant normal effective stress $\left(\sigma_{\mathrm{n}}{ }^{\prime}\right)$ and at a rate of $400 \mathrm{~mm} / \mathrm{min}$ with 10-minute pauses imposed after every $200 \mathrm{~mm}$ shearing. Thereafter the specimens were held under constant $\sigma_{\mathrm{n}}{ }^{\prime}$ for a second stage of consolidation and creep for prescribed durations (see Table 2) which is designed to match the stress conditions acting on the shaft at the time of load test or service loading. The specimens were sheared subsequently at a slow rate of $0.016 \mathrm{~mm} / \mathrm{min}$ for 50-200 mm displacement.

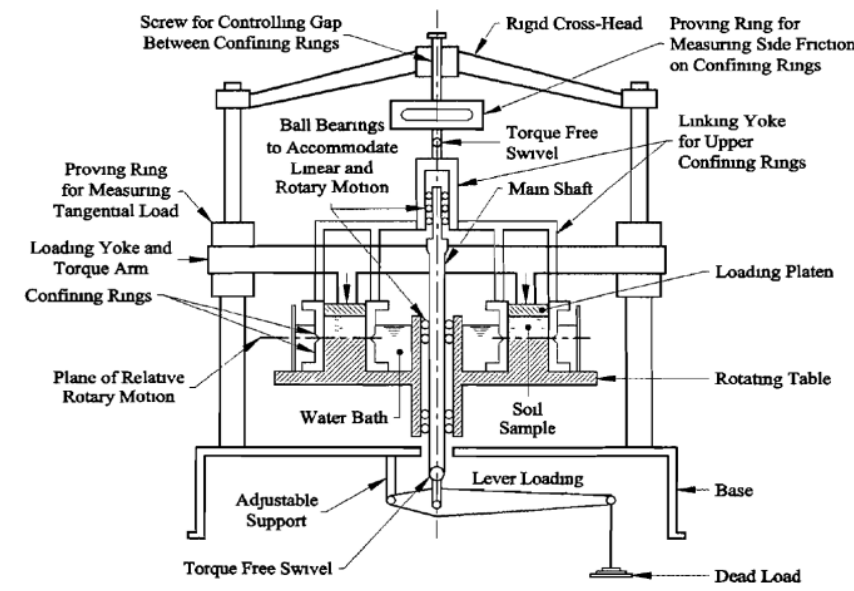

Fig. 3. Bishop ring shear apparatus for soil-soil and soilinterface testing [12-13]

Table 2 Overview of the Bishop ring shear and direct shear interface testing programme

\begin{tabular}{cclcc}
\hline $\begin{array}{c}\text { Test } \\
(1)\end{array}$ & $\begin{array}{c}\text { Sand } \\
(2,3)\end{array}$ & $\begin{array}{c}\text { Interface } \\
\text { Type-Roughness }\end{array}$ & $\sigma_{\mathrm{n}}{ }^{\prime}[\mathrm{kPa}]$ & $\begin{array}{c}\text { Time }^{(5)} \\
{[\text { days }]}\end{array}$ \\
\hline \multirow{4}{*}{$\mathrm{RS}$} & & SS - Smooth & $100-400$ & $0.5,30$ \\
& DK & SS - Rough & $100-400$ & 0.5 \\
& & MS - Medium & 400 & 0.5 \\
& & MS - Rough & $200-1200$ & $0.5,30$ \\
\hline \multirow{2}{*}{ RS } & \multirow{2}{*}{ BL } & SS - Smooth & 200 & 0.5 \\
& & MS - Medium & $100-200$ & 0.5 \\
& & MS - Rough & $200-400$ & $0.5,30$ \\
\hline \multirow{2}{*}{ RS } & \multirow{2}{*}{ LV } & SS - Smooth & 200 & 0.5 \\
& & MS - Rough & $100-400$ & $0.5,30$ \\
\hline \multirow{3}{*}{ DB } & & SS - Smooth & 200 & 0.1 \\
S & DK & SS - Rough & 200 & 0.1 \\
& & MS - Rough & $200-400$ & $0.1-180$ \\
& & MS - Medium & 200 & 0.1 \\
\hline
\end{tabular}

Notes:

(1) RS - Ring Shear; DBS - Direct shear box;

(2) DK - Dunkirk; BL - Blessington; LV - Larvik;

(3) Specimen dry density (in $\mathrm{kg} / \mathrm{m}^{3}$ ): 1610 (DK); 1510 (BL); 1550 (LV)

(4) Steel type: SS - Stainless Steel, MS - Mild steel;
(5) Consolidation and ageing time (in days) applied prior to the final shearing stages.

\subsection{Small-displacement direct shear interface tests without pre-conditioning}

Parallel small-displacement interface tests employing conventional direct shear apparatus were performed on Dunkirk sand. No large-displacement (fast) preconditioning stage can be imposed with such apparatus. The specimens were sheared to failure at a constant displacement rate of $0.1 \mathrm{~mm} / \mathrm{min}$ after the prescribed consolidation (ageing) periods. The nominal shear rate adopted was higher than for the ring shear tests but was deemed to generate negligible effects when testing the relatively coarse Dunkirk sand. The conventional (inferior) interface set-up (steel interface placed underneath deposited sand specimens, [16]), was employed in both the ring shear and direct shear tests. Throughout the testing, the specimens were immersed in a de-ionised water bath that had open access to air but did not add any additional ions to the test assembly.

\subsection{Steel interfaces and surface characteristics}

The potential effects of steel material and surface roughness on interface friction and dilation characteristics were examined by parallel tests with mild and stainless steel interfaces that were either machined to form smooth $\left(R_{\text {CLA }}<2 \mu \mathrm{m}\right)$ surfaces or air-abraded to give medium$\operatorname{rough}\left(2<R_{\mathrm{CLA}}<10 \mu \mathrm{m}\right)$ and rough $\left(10<R_{\mathrm{CLA}}<15 \mu \mathrm{m}\right)$ surfaces, as summarised in Table 2. Interface roughness was measured before and after testing by a Taylor Hobson Talysurf device. Typical vertical profiles obtained from such measurements are demonstrated in Fig. 4.
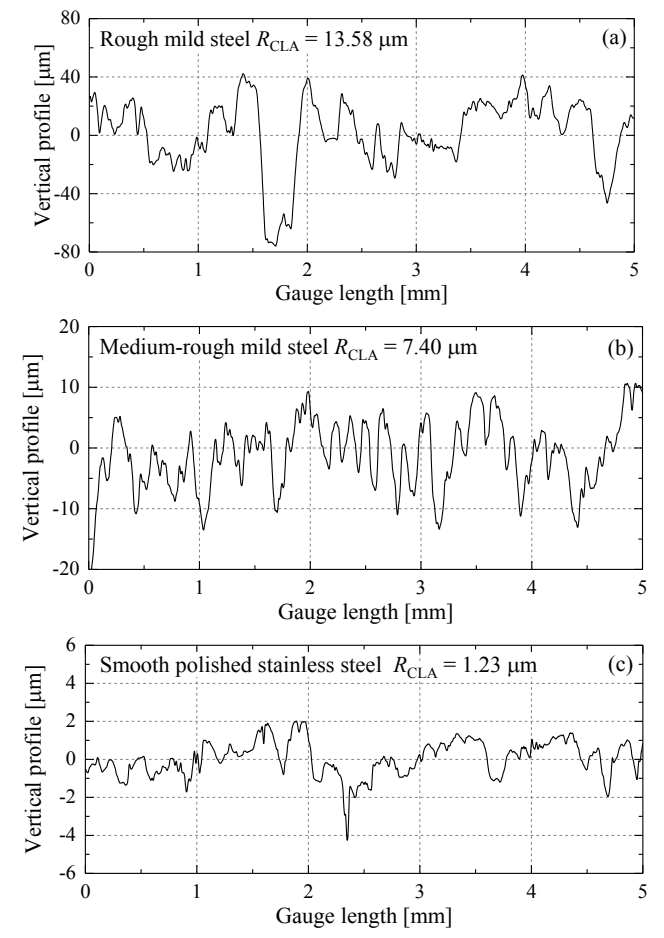

Fig. 4. Examples of vertical surface roughness profiles of (a) rough, (b) medium-rough and (c) smooth steel interfaces 


\section{Test outcomes and discussion}

\subsection{Shear resistance angles characterised from drained triaxial tests}

The discussion focuses first on the sands' angles of shearing resistance, which are often regarded as defining the upper limits for sand-interface friction [21]. Fig. 5 summarises the evolving trends for inter-particle friction angles against axial strains established from the drained triaxial compression tests on sets of water-pluviated, isotropically consolidated specimens conducted at in-situ relative density conditions. Also indicated are the constant volume (or critical state) friction angles $\left(\phi_{\mathrm{cv}}{ }^{\prime}\right)$ identified for each sand.

The very dense Blessington and loose Larvik sands specimens reached their ultimate conditions at lower axial strains than the Dunkirk sand, whose lower $\phi_{\mathrm{cv}}{ }^{\prime}$ value $\left(32^{\circ}\right)$ may reflect its coarser and more uniform grain sizes, as seen in Fig.2.

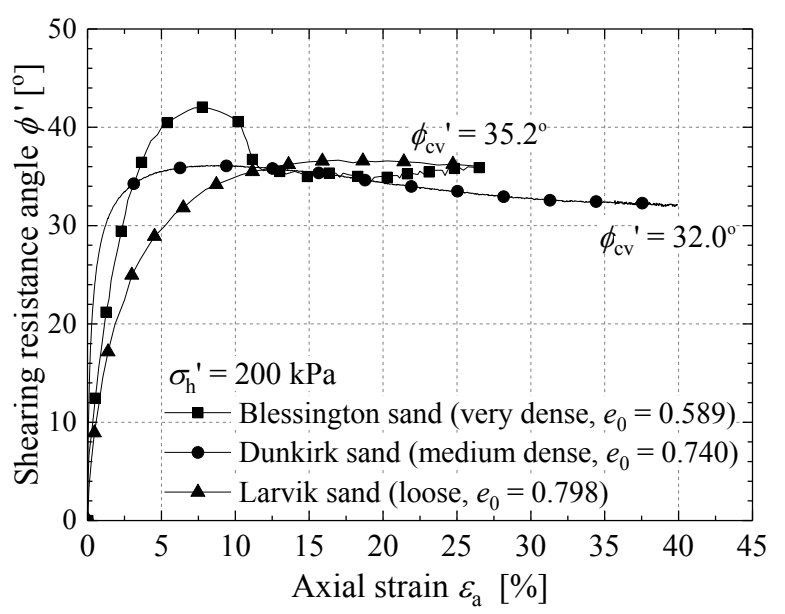

Fig. 5. Evolution of shearing resistance angle against axial strain in drained triaxial tests

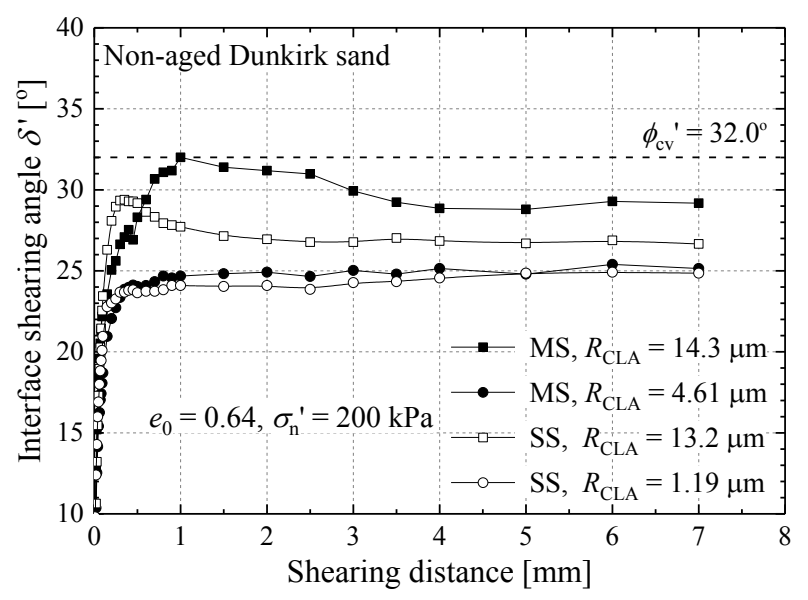

Fig. 6. Effects of steel interface material and surface roughness on interface shearing behaviour of non-aged Dunkirk sand

\subsection{Non-aged and aged small-displacement direct shear interface tests on Dunkirk sand}

Direct shear interface tests on non-aged Dunkirk sand specimens subjected to standard "consolidation" times (0.1 day) revealed the expected impact on interface shearing behaviour of specimen initial density, normal effective stress level and interface surface roughness, conforming to observations reported in previous studies.

Fig. 6 demonstrates how the $\delta^{\prime}$ angles (interpreted as $\left.\delta^{\prime}=\tan ^{-1}\left(\tau_{\mathrm{vh}} / \sigma_{\mathrm{v}}{ }^{\prime}\right)\right)$ varied with interface material and surface roughness in a suite of dense Dunkirk sand specimens $\left(e_{0}=0.64\right)$ under identical $\sigma_{\mathrm{n}}{ }^{\prime}=200 \mathrm{kPa}$ test conditions. Stable angles were noted in all cases after 5 $\mathrm{mm}$ shear displacement. The ultimate friction angles $\delta_{\mathrm{cv}}{ }^{\prime}$, which invariably fell below the $\phi_{\mathrm{cv}}{ }^{\prime}$ value of $32^{\circ}$, depended markedly on interface surface roughness and moderately on steel type.

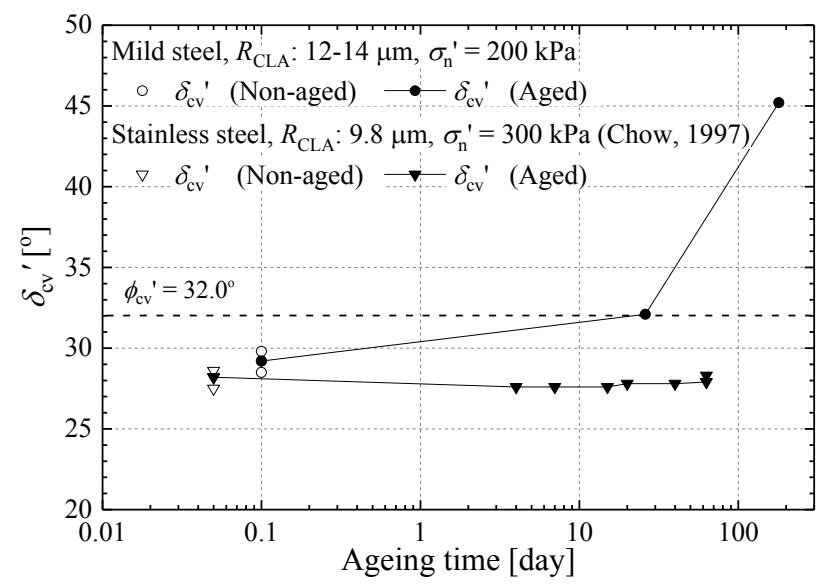

Fig. 7. Effects of ageing on ultimate interface friction angle

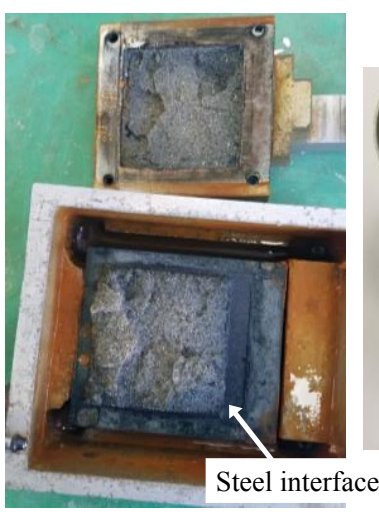

(a)

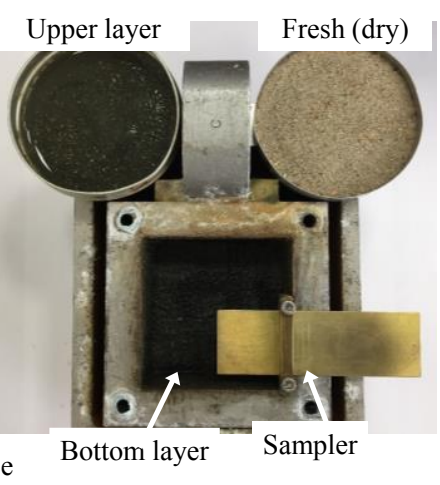

(b)
Fig. 8.Visual inspection made at sand-steel interface after direct shear tests of: (a) 30 day; (b) 180 day ageing

Pronounced time-dependent interface shearing characteristics were observed in the parallel ageing tests performed in direct shear interface tests with mild steel interfaces (see Table 2), with the ultimate interface friction angles $\left(\delta_{\mathrm{cv}}{ }^{\prime}\right)$ increasing remarkably over time, as shown in Fig. 7. The $\delta_{\mathrm{cv}}{ }^{\prime}$ values at 30 and 180 days of ageing exceeded the $\phi_{\mathrm{cv}}{ }^{\prime}$ value of $32^{\circ}$, indicating potential cementation and/or micro-structural changes under long- 
term ageing. Also integrated in Fig. 7 are test outcomes from a suite of direct shear ageing interface tests on a similar batch of Dunkirk sand reported by [22], noting however that the tests were performed with stainless steel interfaces, which are inert to physiochemical reactions. The steel properties and the associated physiochemical processes occurring in the steel-sand-water system, which had free access also to air, are important factors that contribute to the time-dependent interface shearing behaviour of steel field piles.

The long-term physiochemical process clearly affected the direct shear test interfaces and sand masses. As shown in Fig. 8, the interfaces became coated with a rusted layer of dark green and deep black corrosion product, indicating redox reactions which also extended into the sand mass. Similarly prominent changes to the colour and topography of the sands and steel interfaces were observed in the ring shear tests discussed below, as well as over the shafts of the micro-piles, as reported by [9] from their pile exhumation observations.

\subsection{Large-displacement Bishop ring shear interface tests with pre-conditioning}

Marginal changes to particle size and interface surface roughness were noted in the small-displacement direct shear interface tests. However, far greater changes took place in the ring shear tests that incorporated fast, largedisplacement conditioning stages. Visual observation and quantitative measurements confirmed significant grain crushing and interface smoothing under even relatively low normal stresses $(<200 \mathrm{kPa})$. The resulting mutated sands and interfaces exhibited interface shearing characteristics that could be expected to differ from those commonly observed in conventional direct shear interface tests.

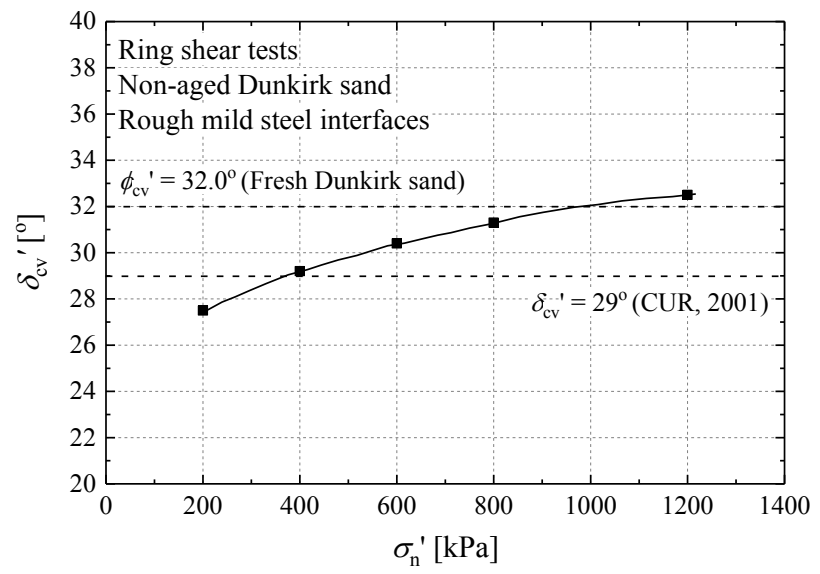

Fig. 9. Dependency of ultimate friction angles $\left(\delta_{\mathrm{cv}}\right)$ on normal stress levels $\left(\sigma_{\mathrm{n}}{ }^{\prime}\right)$ observed in the ring shear tests

Clear stress-dependency of interface friction angles was observed with the three sands. Fig. 9 demonstrates the trend of ultimate friction angle against normal effective stress level observed in the suite of ring shear tests performed with rough mild steel interfaces on non-aged Dunkirk sand specimens. The interface friction angles increased consistently with normal stresses and exceeded, although marginally, the $\phi_{\mathrm{cv}}{ }^{\prime}$ value for untested Dunkirk sand under the highest $\sigma_{\mathrm{n}}{ }^{\prime}$ of $1200 \mathrm{kPa}$. As also indicated in Fig. 9, the $\delta_{\text {cv }}{ }^{\prime}$ values clearly vary from the single value of $\delta_{\mathrm{cv}}{ }^{\prime}=29^{\circ}$ recommended by [23], demonstrating the importance of the site- and case-specific interface testing recommended by [1].

Similar dependency on normal effective stress was also observed in the parallel ring shear tests with stainless steel interfaces, regardless their surface roughnesses. The stress-dependent characteristics can also be inferred from [16] $\delta_{\mathrm{cv}}{ }^{\prime}-D_{50}$ trends that the $\delta_{\mathrm{cv}}{ }^{\prime}$ values are higher under greater $\sigma_{\mathrm{n}}{ }^{\prime}$ over larger $D_{50}$ (coarser) range that significant crushing occurs.

Increasing trends of $\delta_{\mathrm{cv}}{ }^{\prime}$ with $\sigma_{\mathrm{n}}{ }^{\prime}$ were also noted in the tests on Blessington and Larvik sands, although the magnitudes varied with the sands' index properties and chemical compositions (see Table 1). Blessington sand exhibited the most prominent stress-dependent interface shearing properties among the three sands studied.

Fig. 10 demonstrates again the effects of ageing observed in ring shear interface tests, drawing on results from two Dunkirk sand specimens aged for 0.5 and 30 days respectively under $\sigma_{\mathrm{n}}{ }^{\prime}=200 \mathrm{kPa}$ when sheared against rough mild steel interfaces. Significant timedependency of friction angle was noted in ring shear interface tests. [11] summarised full details of the test outcomes and consider the other ageing test scenarios listed in Table 2. Further interpretation and explanation of the ageing mechanisms is provided based on laboratory observations that aid the understanding of ageing gain of axial capacity of steel piles driven in sand, as illustrated in Fig. 1. Long duration ageing periods in ring shear interface tests clearly provide valuable information.

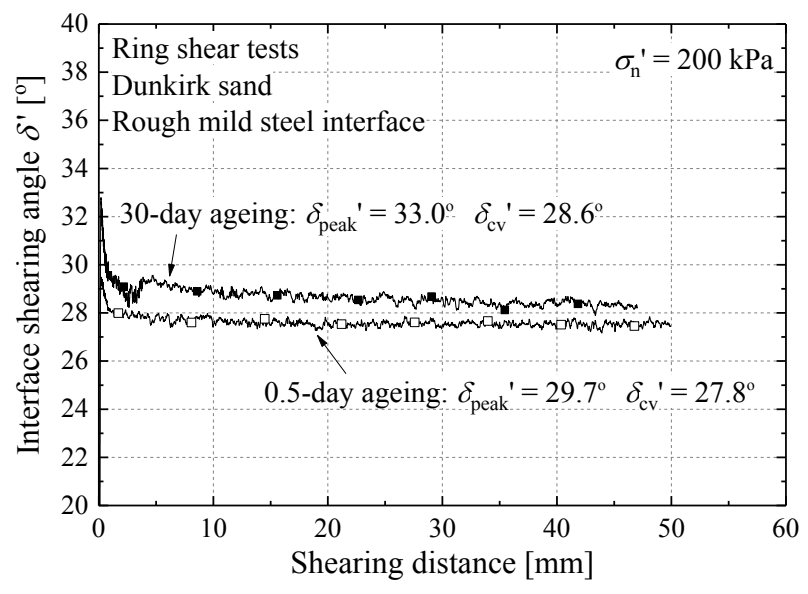

Fig. 10. Effects of ageing on the interface friction angles of Dunkirk sand shearing against rough mild steel interfaces

\section{Conclusions}

A comprehensive laboratory study of the sand-steel interface shearing behaviour of Dunkirk, Blessington and Larvik sands has been completed in parallel with field pile tests that examined the mechanisms of axial shaft capacity for steel pipe piles driven in sand. The illustrative test 
results that focus on Dunkirk sand presented and discussed above lead to the following main conclusions.

(1) Significant micro-structural and physio-chemical changes can occur during both pile installation and over time due to grain crushing and soil-steel-waterair interaction processes that lead to interface friction angles changing during pile driving and growing over time to match or exceed the fresh soils' critical state $\phi^{\prime}$ values.

(2) Marked stress-dependency of interface friction angles was observed in the ring shear tests that incorporated pre-conditioning shearing.

(3) Significant ageing effects were noted in both smalland large-displacement interface tests performed with mild steel interfaces, primarily due to long-term compaction and physicochemical reaction.

(4) Site-specific ring shear tests that impose preconditioning stages are strongly recommended as the best means of deriving representative sand-structure interface shearing parameters for detailed design of driven piles. Small-displacement direct shear or other type of interface tests may be required for other practical applications, such as retaining walls or shallow foundations.

(5) It is valuable to incorporate ageing periods when conducting such interface tests to model long-term service performance.

The Blessington and Larvik sand samples were kindly provided by Prof. Ken Gavin (TU Delft) and Dr. Roselyn Carroll (NGI). The Authors are indebted to Mr. Steven Ackerley and Mr. Graham Keefe at Imperial College London for upgrading the Bishop ring shear apparatuses and providing invaluable technical support. Mr. Derek Chan and Mr. Ken Vinck are acknowledged for their kind assistance. The financial support provided to the first Author by an IC-CSC scholarship and Ørsted is acknowledged.

\section{References}

1. R. J. Jardine, F. C. Chow, R. F. Overy, and J. R. Standing, ICP design methods for driven piles in sands and clays. London, Thomas Telford (2005)

2. B. Byrne, R. McAdam, H. Burd, G. Houlsby, C. Martin, W. Beuckelaers, L. Zdravkovic, D. Taborda, D. Potts, R. J. Jardine, E. Ushev, T. Liu, D. Abadias, K. Gavin, D. Igoe, P. Doherty, J. S. Gretlund, M. P. Andrade, A. M. Wood, F. Schroeder, S. Turner, and M. Plummer, PISA: New design methods for offshore wind turbine monopiles. In 8th International Conference on Offshore Site Investigation \& Geotechnics, London, UK (2017)

3. F. C. Chow, R. J. Jardine, F. Brucy, and J. Nauroy, J. Geotech. Geoenv. Eng., 124, 3, 254-264 (1998)

4. R. J. Jardine, J. R. Standing, and F. C. Chow, Géotechnique, 56, 4, 227-244 (2006)

5. K. G. Gavin, D. J. P. Igoe, and L. Kirwan, Proceedings of the Institution of Civil Engineers Geotechnical Engineering, 166, 2, 122-130 (2013)

6. K. Karlsrud, T. G. Jensen, E. K. Wensaas Lied, F. Nowacki, and A. S. Simonsen, Significant ageing effects for axially loaded piles in sand and clay verified by new field load tests. In Proceedings of the
Offshore Technology Conference, Houston, TX, USA, pp. paper OTC-25197-MS (2014)

7. S. Rimoy, M. Silva, R. J. Jardine, Z. X. Yang, B. T. Zhu, and C. H. C. Tsuha, Géotechnique, 65(7):576589 (2015)

8. Z. X. Yang, W. B. Guo, R. J. Jardine, and F. Chow, Can. Geotech. J., 54, 1, 59-74 (2017)

9. R. Carroll, P. Carotenuto, C. Dano, I. Salama, M. Silva, S. Rimoy, K. Gavin, and R. J. Jardine, under review by Géotechnique (2018)

10. H. Chen, MSc thesis, Imperial College London (2017)

11. T. F. Liu, PhD thesis, Imperial College London (2018)

12. A. W. Bishop, G. E. Green, V. K. Garga, A. Andresen, and J. D. Brown, Géotechnique, 21, 4, 273-328 (1971)

13. N. Ramsey, R. J. Jardine, B. Lehane, and A. Ridley, A review of soil-steel interface testing with the ring shear apparatus. In Offshore Site Investigation and Foundation Behaviour. Society of Underwater Technology, London, UK (1998)

14. Z. X. Yang, R. J. Jardine, B. T. Zhu, P. Foray, and C. H. C. Tsuha, Géotechnique, 60, 6, 469-482 (2010)

15. I. Barmpopoulos, T. Ho, R. J. Jardine, and N. AnhMinh, The large displacement shear characteristics of granular media against concrete and steel interfaces. In Proceedings of the Research Symposium on Characterization and Behavior of Interfaces. (Frost, J. (ed)) IOS press, Atlanta, USA (2010)

16. T. Ho, R. J. Jardine, and N. Anh-Minh, Géotechnique, 61, 3, 221, (2011)

17. V. S. Quinteros, R. Dyvik, and N. Mortensen, Interface friction angle from ring shear tests on offshore North Sea sands. In Geotechnical Frontiers 2017. (Brandon, T. L., and Valentine, R. J. (eds)) ASCE, Orlando, USA, vol. GSP 280 (2017)

18. L. H. D. Chan, R. M. Buckley, T. F. Liu, and R. J. Jardine, Laboratory investigation of interface shearing in chalk. In IS-Glasgow (2019)

19. T. F. Liu, V. S. Quinteros, R. J. Jardine, J. A. H. Carraro, and J. Robinson, A unified database of ring shear steel-interface tests on sandy-silty soils. Submitted to ECSMGE, Reykjavik (2019)

20. F. N. Altuhafi, R. J. Jardine, V. N. Georgiannou, and W. W. Moinet,Géotechnique, 68, 6, 546-555 (2017)

21. M. Uesugi, and H. Kishida, Soils Found., 26, 2, 33$46(1986)$

22. F. C. Chow, $\mathrm{PhD}$ thesis, Imperial College (University of London) (1997)

23. CUR Bearing capacity of steel pipe piles, Report 2001-8. Gouda, The Netherlands, Centre for Civil Engineering Research and Codes (2001) 